\title{
REVIEW
}

\section{Gold and nano-gold in medicine: overview, toxicology and perspectives}

\author{
Nagender Reddy Panyala ${ }^{1}$, Eladia María Peña-Méndez ${ }^{2}$, Josef Havel ${ }^{1,3}$ \\ ${ }^{1}$ Department of Chemistry, Faculty of Science, Masaryk University, Brno, Czech Republic \\ ${ }^{2}$ Department of Analytical Chemistry, Nutrition and Food Chemistry, Faculty of Chemistry, University of La \\ Laguna, La Laguna, Tenerife, Spain \\ ${ }^{3}$ Department of Physical Electronics, Faculty of Science, Masaryk University, Brno, Czech Republic
}

Received $21^{\text {st }}$ March 2009.

Revised $23^{\text {rd }}$ May 2009.

Published online $9^{\text {th }}$ June 2009.

\begin{abstract}
Summary
Nano-technology has entered the field of medicine in recent decades and many of the nanomaterials developed have already had a high impact on health care. Among nanomaterials, gold nanoparticles (GNPs) and gold quantum dots (QDs) are receiving significant attention because their unique physical, chemical and biological properties are quite different from the bulk of their counterparts. In this article, after a brief historical overview, the use of gold and nano-gold in medicine is reviewed, analyzed, and discussed. The review particularly deals with the use of GNPs and bio-conjugated GNPs in cancer treatment, drug or gene delivery, DNA detection, biomedical imaging including that of brain activity, enhancement of gene regulation, the detection of toxic metals, immuno-assays, disease detection and diagnostics, therapy and also the toxicity of gold and GNPs, etc. A number of novel applications of GNPs in medicine and perspectives of nano-gold use in medicine are also discussed.
\end{abstract}

Key words: gold nanoparticles; gold quantum dots; nanomedicine; biomolecules; toxicity

\section{INTRODUCTION}

Nanotechnology is a rapidly growing science which deals with structures with at least one dimension of the size of one hundred nanometres or less and involves producing materials and devices of that size. Nanotechnology is focused on the integration of fields such as physics, biology, engineering, chemistry, computer science and others.

\begin{tabular}{|c|c|}
\hline$\triangle$ & $\begin{array}{l}\text { Josef Havel, Department of Chemistry } \\
\text { and Department of Physical Electronics, } \\
\text { Kotláŕská 2, } 61137 \text { Brno, Czech Republic }\end{array}$ \\
\hline$\square$ & Havel@chemi.muni.cz \\
\hline 要 & +420549494114 \\
\hline 且 & +420549492494 \\
\hline
\end{tabular}

Nanomaterials have been extensively studied in the last few years. For example, in our laboratory we have recently studied nanodiamonds (NDs) and various clusters (Houška et al. 2008, 2009a, b). Among these nanomaterials, nanoparticles (NPs) are now playing a crucial role in the field of nanotechnology. Over a few years the use of NPs has brought a new era to the field of nanomedicine and has altered the foundations of disease diagnosis, treatment and prevention based on their properties. Furthermore, there is a wide array of fascinating nanoparticulate technologies capable of targeting different cells and extra cellular elements in the body to deliver drugs, genetic materials, and diagnostic agents specifically to these locations (Brigger et al. 2002, Paciotti et al. 2004, Jain 2005, Moghimi et al. 2005, Mukherjee et al. 2005, Cuenca et al. 2006, Kam et al. 2006, Zhang et al. 2006, Bhattacharya et al. 2007). The strong optical 
absorption of GNPs, their scattering properties, and low or complete lack of toxicity have made them a promising class of nanomaterials for the development of novel biomedical applications.

Within nanotechnology, GNPs have attracted great attention due to their unique electronic, optical, thermal, chemical, biological properties and their potential catalytic applications in various fields such as biology, medicine, physics, chemistry, material science and other interdisciplinary fields (Salata et al. 2004). Biocompatible GNPs labelled with specific targeting biomolecules/drugs, in site specific delivery, are playing a key role in the diagnosis and therapy of several incurable diseases, for example, in cancer treatment. The physical, chemical and biological properties of materials at the nano-scale differ from corresponding bulk counterparts. For example, GNPs are typically wine red in colour whereas metallic gold is yellow in colour. The colour of nanoparticles varies with their size and shapes. Gold atoms can aggregate themselves under various conditions and can form GNPs by sequential aggregation. Gold clusters can be formed by various methodologies. For example, charged gold $\left(\mathrm{Au}_{n}^{+}\right)$clusters are formed by laser desorption/ionization (LDI) of Au(s) or Au salts such as auric acid $\left(\mathrm{HAuCl}_{4}\right)$ where $\mathrm{Au}_{n}^{+}$clusters with $n$ up to 1-25 were detected (Peña-Méndez et al. 2008). An example of mass spectra concerning the formation of gold clusters is given in Fig. 1.

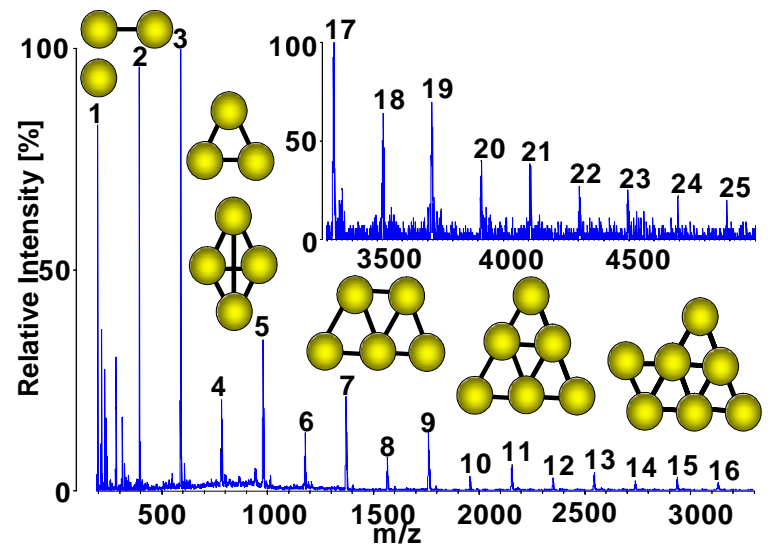

Fig. 1. Part of Laser Desorption Ionisation TOF mass spectrum showing the formation of gold clusters $\mathrm{Au}_{n}{ }^{+}$ ( $n=1-25)$. Conditions: commercial MALDI TOF MS instrument (Axima-CFR. Shimadzu Biotech, U.K.) with a pulsed nitrogen laser of a wavelength of $337 \mathrm{~nm}$; linear positive ion mode, laser energy 100 arbitrary units (A.U.).

GNPs are also synthesized from the reduction of gold salts by various reducing agents such as gallic acid, $\mathrm{H}_{2} \mathrm{O}_{2}$, hydrazine, etc. (Panda et al. 2007, Wang et al. 2007). GNPs represent several different shapes, i.e. gold nanorods, gold nanospheres, star-like GNPs, etc. The shape of GNPs plays a major role in the uptake of GNPs into cell lines. Chithrani et al. (2006) investigated the intracellular uptake of GNPs with different size and shape into mammalian cells. They have concluded that kinetics and saturation concentrations are highly dependent upon the physical dimensions of the nanoparticles. This finding will have implications in the chemical design of nanostructures for biomedical applications. The optical properties of GNPs are also dependent on their shape (Nehl et al. 2006, 2008).

\section{Quantum dots}

Quantum dots are semi-conducting nanocrystals which have quantum optical properties due to the confinement of their excitons in all three spatial dimensions. These non-fluorescent compounds develop intense, long-lasting colours excitable by UV and visible light-emitting diodes, lasers, etc. due to their incredible small size $(2-100 \mathrm{~nm})$. The colours produced are a function of the particle size and this function depends on the diameter of the nanocrystals. The fluorescence is due to a phenomenon called quantum confinement.

QDs have ideal properties and their applications as biological tags in ultra sensitive biological detection have been extensively investigated (Bruchez et al. 1998, Chan et al. 1998, 2002). They are preferable to the conventional organic fluorophores due to their strong, narrow emission spectrum, and photochemical stability. They also display a wide range of size tunable colours. So it is possible that a series of different coloured dots can be activated at the same time using a single laser. The surface modification of QDs for various bio-applications has been studied (Tan et al. 2005). Applications of QDs in photodynamic and radiation therapies for cancer have been recently reviewed extensively (Juzenas et al. 2008).

Although several reviews have been published concerning the applications of GNPs in medicine, the aim of this particular review is to overview the most recent papers concerning new applications of GNPs in medicine, and to summarize and/or discuss various aspects of these applications not sufficiently discussed in the literature and also to overview the possible toxic effects of GNPs on human health.

Forms of gold

Although gold is a noble metal and a commonly used material because of its resistance to oxidation and 
interesting electrical, magnetic, optical, and physical properties, it forms many and diverse compounds. The oxidation state of gold in its compound ranges from -1 to +5 , but $\mathrm{Au}(\mathrm{I})$ and $\mathrm{Au}(\mathrm{III})$ dominate. Gold(I), referred to as the 'aurous ion', is the most common oxidation state and reacts with "soft" ligands such as thioethers, thiolates, and tertiary phosphines. Only salts and radioisotopes of gold are of pharmacological value, as elemental (metallic) gold is inert to all chemicals it encounters inside the body. Pure gold is non-toxic and non-irritating when ingested (http://www.espi-metals.com $/ \mathrm{msds} \% 27 \mathrm{~s} / \mathrm{g}$ old.htm) and is sometimes used as a food decoration in the form of gold leaf. Gold is even approved as a food additive in the European Union.

While metallic gold is non toxic, gold salts are; e.g. gold chloride is a neurotoxin and known to cause peripheral neuropathy. Soluble gold salts such as potassium gold cyanide, used in gold electroplating, are toxic to the liver and kidneys. There are rare cases of lethal gold poisoning from potassium gold cyanide. Gold toxicity can be ameliorated with chelation therapy with an agent such as Dimercaprol (Wright et al. 1986, Wu et al. 2001). Even if metallic gold in living organisms is considered non-toxic and no oxidation reactions are known up to now, this oxidation problem requires attention.

\section{Gold as a medicine: Historical overview}

The use of GNPs has been known throughout history and alchemists referred to them as a possible "Elixir of Life". Gold was already being used by the Chinese as a medicine in 2500 B.C. In India, colloidal red gold was used in the form of ayurvedic medicine for rejuvenation and revitalization during old age, and was called "Swarna Bhasma" (Mahdihassan 1971, 1981). Cinnabar-gold, also known as "Makaradhwaja" (Mahdihassan 1985) is used as a drug for youthful vigour in India. Gold was for a long time used as a drug, called "nervin" for the revitalization of people who are suffering from nervous disorders (Fricker et al. 1996). In the $16^{\text {th }}$ century, gold was recommended for the treatment of epilepsy (Daniel et al. 2004) for which Paracelsus created a potion called Aurum Potabile. Colloidal gold was used to colour glass yellow or red and the colour of the famous bohemian ruby glass is also obtained from nano-gold. Herschel used colloidal gold to record images on paper in 1842 . However, the modern scientific evaluation of colloidal gold did not commence until 1857, when Michael Faraday learned by experiment that the colour of gold solutions was due to the small size of gold particles. In the beginning of the $19^{\text {th }}$ century, gold was used as a drug for the treatment of syphilis (Daniel et al. 2004). The therapeutic use of gold was established for the first time when Robert Koch discovered the bacteriostatic effect of gold cyanide on Mycobacterium tuberculosis, following which the medicinal use of gold for the treatment of tuberculosis was introduced in the 1920s (Daniel et al. 2004). Gold and gold compounds are mainly applied as a drug for the treatment of rheumatic diseases including psoriasis, palindromic rheumatism, juvenile arthritis and discoid lupus erythematosus (Felson et al. 1990 and Shaw 1999). Rheumatoid arthritis (RA) is a form of arthritis that causes pain, swelling, stiffness and loss of function in joints. It can affect any joint of the body but is common in the wrist and fingers. The most important drugs for the treatment of RA are gold thiolates, and prime examples of these are sodium aurothiomalate and aurothioglucose. Following the body's extensive exposure to these gold thiolate drugs, the gold can diffuse to various organs such as the liver, kidney and spleen (Bhattacharya et al. 2008). The adsorption of gold in the kidney causes nephrotoxicity. In addition, several adverse effects such as skin irritation, mouth ulcers, liver toxicity and blood disorders have been associated with prolonged exposure to gold compounds (Bhattacharya et al. 2008). To avoid these poor pharmacokinetics and toxicity, a safe and superior second generation drug, auranofin (AF) was introduced for the treatment of arthritis. A critical case study was carried out on the efficacy and toxicity of AF by Glennås et al. (1997), which found that AF can be more lipophilic and has better retention in the circulation due to the presence of phosphine-ligands. Also renal toxicity has been reduced by the use of $\mathrm{AF}$ in comparison with the parental gold (Bernhard 1982). Subsequently, phosphines containing gold drugs received great attention and are considered as suitable drugs for the treatment of cancer, as they exhibit potential anti-tumour properties; however, when used in clinical trials they have caused cardiovascular toxicity. The mechanism of action for these drugs has been poorly understood. However, it is believed that under biological conditions, gold (I) and gold (III) species can be reduced to gold (0). Recently, Bhattacharya et al. (2008) reported, for the first time, the anti-angiogenic properties of gold. Even though there are many papers published concerning gold applications in medicine (Mukherjee et al. 2007, Cai et al. 2008) this paper discusses the more recent and most important applications of GNPs and attempts to put them in perspective.

The role of gold and/or GNPs in medicinal applications as a direct medicine (active medicine) and as an additive to drugs or biomolecules (passive medicine) will be discussed in individual chapters. 
Any discussion of the medical applications of GNPs cannot be dealt with in discrete chapters and there will inevitably be some overlapping of topics as new perspectives are brought into play.

\section{GOLD AS AN ACTIVE MEDICINE}

Gold, designated as an active medicine, has been used for the treatment of various autoimmune diseases and for RA. In this section, selected examples of various drugs containing gold and their medicinal applications are discussed, while their potential toxic effects are also considered.

Gold has been used for the treatment of RA for several years. The cause of RA is still unknown and autoimmunity plays a pivotal role in its chronicity and progression. RA is a chronic, systemic inflammatory disorder, which mainly attacks the joints producing an inflammatory synovitis that often leads to the destruction of the articular cartilage and ankylosis of the joints. In addition, RA can also produce diffuse inflammation in the lungs, pericardium, pleura, sclera, and nodular lesions are the most common symptoms in subcutaneous tissue. Although gold and gold compounds had been used for some time in the treatment of disease it was not until 1927 that aurothioglucose was used for the first time in the treatment of RA by Landé (1927). Gold thiopropanol sodium sulfanate was used in more than 550 cases of RA with beneficial results by Forestier in 1935. Subsequently, several gold compounds were developed and clinical trials confirmed Forestier's results (Forestier 1935).

Gold therapy is available in two forms: injection and the oral route. Clinical benefits have been achieved from treatment with one of these two therapies. Both therapies have highly significant side-effects and should be considered as toxic but the oral preparation appears to have a better safety profile than the injectable compound (Davis 1988).

\section{Gold therapy with auranofin}

The treatment of certain diseases, especially RA, with gold compounds is known as Chrysotherapy. Auranofin (AF) is the name of an effective gold compound which has been used for the treatment of rheumatoid arthritis. The exact mechanism of action is still unknown, but it probably acts via immunological mechanisms and the alteration of lysosomal enzyme activity. Although AF has limited long term clinical experience, its efficacy appears to approach that of sodium aurothiomalate (an injectable form of gold). AF is suitable for most RA patients, but patients with diarrhoea, skin rash, and pruritus are sometimes troubled, and thrombocytopenia and proteinuria are potentially serious adverse effects which may occur during the therapy. Mucocutaneous side effects are more frequent with injectable gold compounds and gastrointestinal reactions are the most common adverse effects seen with AF. Auranofin and sodium aurothiomalate have the same frequency of side effects, but they are generally less severe with auranofin. Although there are adverse effects, such effects can be controlled by a reduction in dosage although temporary or permanent withdrawal of AF may be necessary. A combination of AF with disease-modifying potential agents is presently available for the treatment of rheumatoid arthritis. This therapy will generate significant interest as it acquires a better place in therapy through additional well-designed investigations and wider clinical experience (Chaffman et al. 1984).

$\mathrm{AF}$ is also showing potential antimalarial activity beyond its anti-arthritic properties. Recently the anti-malarial activity of auranofin has been reported (Sannella et al. 2008); it seems that it acts as a potential inhibitor of mammalian thioredoxin reductases which cause oxidative stress. The authors conclude that it exhibits potential antiplasmodic activity, which means that AF could inhibit the growth of Plasmodium palsifarum, the pathogen which causes the malaria disease. The combination of artemisinin (an anti-malarial drug) and AF showed additional antimalarial effects (Sannella et al. 2008).

\section{Gold therapy with aurothioglucose}

It is thought that an immune system response may contribute to arthritis. Gold may affect this response and decelerate the progression of the disease. Aurothioglucose (ATG, Solganal ${ }^{\circledR)}$ ), also known as gold thioglucose, is a glucose derivative used to treat RA. It reduces the inflammation and swelling due to arthritis. Aurothioglucose is used to treat only the early stages of adult or juvenile (childhood) rheumatoid arthritis and it is not effective in treating advanced cases of arthritis. Although ATG exhibits anti-rheumatic activity, it also presents adverse effects such as blood in urine, mouth sores, fever, skin rash or itching, unusual tiredness, swelling of eyes and face, etc. (http://www.uamshealth.com/HealthLibrary, viewed on $21^{\text {st }}$ March 2009).

\section{HIV therapy}

NF- $\mathrm{B}$ (nuclear factor kappa-light-chain-enhancer of activated $B$ cells) is a protein complex that acts as a transcription factor, which is a potent cellular activator of HIV-1 gene expression. Traber et al. (1998) reported that ATG significantly inhibited 
TNF- $\alpha$ induced HIV-1 replication in latently infected cells and also reported its efficacy as an inhibitor of HIV replication in latently infected OM10.1 and Ach2 cells. The tumour necrosis factor (TNF $\alpha$ )-induced HIV-1 replication in OM10.1 [a human immunodeficiency virus type-1 (HIV-1)-infected promyelocytic cell line, designated as OM, derived from HL-60 cells] or Ach2 cells (Ach-2 is a clone that survived infection and that constitutively produces low levels of reverse transcriptase) was significantly inhibited by non-cytotoxic doses of ATG $(>10 \mu \mathrm{M}$ in OM10.1 cells and $>25 \mu \mathrm{M}$ in Ach2 cells). The effect of ATG on NF- $\kappa \mathrm{B}$-dependent gene expression was confirmed by a transient CAT assay (An enzyme assay. CAT stands for chloramphenicol acetyl transferase enzyme). Electron microscopic examinations, as well as specific staining, revealed the accumulation of metal gold in the cells, indicating that gold ions could block NF-B-DNA binding by a redox mechanism (Traber et al. 1998). It was concluded that the monovalent gold compound ATG is a potentially useful drug for the treatment of patients infected with HIV.

\section{GNP AS A PASSIVE MEDICINE}

Due to their unique properties, GNPs have been used as an additive to various drugs, and are in this respect designated as a passive medicine; We will discuss here the recent novel applications of GNPs as a passive medicine.

\section{GNPs in cancer treatment}

Conventional strategies for the treatment of cancer are surgery, radiation therapy and chemotherapy but cancer nanotechnology is a fascinating field with broad applications in the fight against cancer, which include molecular imaging, molecular diagnosis, and targeted therapy. GNP applications in cancer treatment have been investigated recently, because of the unique properties of GNPs. Laser irradiated gold nanorods, nanospheres, nanoshells, and nanocages can kill bacteria and cancer cells (Zharov et al. 2006, Chen et al. 2007). According to Gannon et al. (2008), lasers have been used in clinical diagnosis to treat malignant tumours, but the procedure presents a number of difficulties (Bilchik et al. 2000, Bleicher et al. 2003, Curley et al. 2004, Haemmerich et al. 2005). These limitations include: 1) laser ablation is an invasive treatment because it requires insertion of needle electrodes directly into the tumours; 2) the treatment is non-specific as it causes thermal injury to normal tissues together with malignant tissues; 3 ) there is the possibility of incomplete tumour destruction; and 4) invasive laser ablation treatment of tumours is limited to a few organ sites (liver, kidney, breast, lung, and bone) (Gannon et al. 2005, Raut et al. 2005). Although laser ablation methods have limitations, GNPs have been used extensively to detect and destroy cancerous cells.

GNPs can act as chemical carriers to deliver drugs to a targeted location to destroy a cancer cell or they can be used together with radiation. Radio frequencies are used to heat GNPs. The heated nanoparticles in turn heat, and destroy the cancer cell. These radio waves might not harm the healthy cells. Infrared light waves can be used in place of radio waves to heat up the cancer cells for destruction, but, in reality, the laser mediated destruction of tumour cells requires intracellular and intra-tumoral agents that release heat under the influence of a radio frequency field. Also required are suitable agents that have little or no intrinsic cellular or tissue toxicity to malignant tumour cells and not harmful to healthy cells. Potentially these non-invasive techniques for the treatment of cancers, with minimal or no toxic effects, could be highly beneficial (Gannon et al. 2008). An instance of this, according to Patra et al. (2007), is GNP induced apoptosis (cell death) in the human carcinoma lung cell line A549. For comparison, the process was checked with another two cell lines, i.e., BHK21 (baby hamster kidney) and HepG2 (human hepatocellular liver carcinoma), and no effects in BHK21 and HepG2 cell lines were observed. These results demonstrated that the specificity of induction for the death response in A549 cells indicated that GNPs do not target all cell type indiscriminately, but are specific to a few cell lines. Flow cytometric studies have shown a dose dependent threshold effect in this death response (Patra et al. 2007).

Recently, Bhattacharya et al. (2008) reviewed the use of GNPs in cancer therapy. So called coated GNPs with specific antibodies represent a promising alternative as probes for the detection of antigens on the surfaces of cells. The interaction between GNPs and proteins has been known for some time (Krasovskii et al. 2007, Dobrovolskaia et al. 2008) and has been applied in the immunogold labelling technique in which GNPs labelled with antibodies are used to mark specific cells and act as a probe for the transmission of the scanning electronic microscopy observations (Faulk and Taylor 1979). By electron microscopy observation, the immunogold labels appear as extremely dense round spots at the position of the antigen in ultra thin sections of tissues (Roth et al. 1981).

Lu et al. (2009) used tiny hollow gold spheres 
with a highly targeted peptide to hunt down and penetrate deep inside melanoma cells destroying them using heat converted from infra red light. This technique utilized tiny gold spheres, 40 to 50 nanometres in diameter, their hollowness allowing them to penetrate the cancer cells. The hollow gold spheres have a strong but narrow and tunable ability to absorb light at the visible and near-infrared end of the spectrum, whereas other metal nanoparticles do not. Photo thermal ablation, a minimally invasive treatment in which the target tissue is destroyed by irradiating the target area with light, was applied to live lab mice. The light is converted to heat and destroys the surrounding tissue. However, it is not easy to treat melanomas using this method due to the difficulty in aiming nanoparticles and differentiating between healthy and cancerous tissue. To avoid this problem, a peptide, was embedded in the gold nanospheres. The peptide was highly target specific and it could only bind to the melanocortin type 1 receptor, which is excessively abundant in melanoma cells (Lu et al. 2009).

When gold nanosphere treated melanoma cell cultures are irradiated, the majority of cells containing the targeted nanospheres die, and nearly all those left are damaged beyond repair. When untargeted nanospheres are used, only a very small fraction of treated cells die (Lu et al. 2009).

Laser induced explosion of GNPs have been used for the selective nanophotothermolysis of cancerous cells. Letfullin et al. (2006) demonstrated that when GNPs are irradiated with short laser pulses, their temperature rises very rapidly and it leads to the formation of nonlinear effects such as micro bubble formation, acoustic and shock wave generation and the abnormal cancerous cell are destroyed. By engineering laser wavelength, laser pulse duration, nanoparticles size and shape, this method can provide highly localized cancer cell damage in a controlled manner without damaging the surrounding healthy tissue. Thermal explosion is realized when heat is generated within a strongly absorbing target more quickly than the heat can diffuse away. It is demonstrated that on the basis of simple energy balance, the threshold energy density of a single laser pulse required for the thermal explosion of a solid gold nanosphere is $\sim 40 \mathrm{~mJ} / \mathrm{cm}^{2}$ (Letfullin et al. 2006). A schematic presentation of the laser induced explosion of GNPs for the treatment of cancer is shown in Fig. 2.

GNPs as drug or gene carriers or vectors There is great interest in finding pharmaceutically active particles to mediate the targeting of cell types. Monoclonal antibodies have been used for the

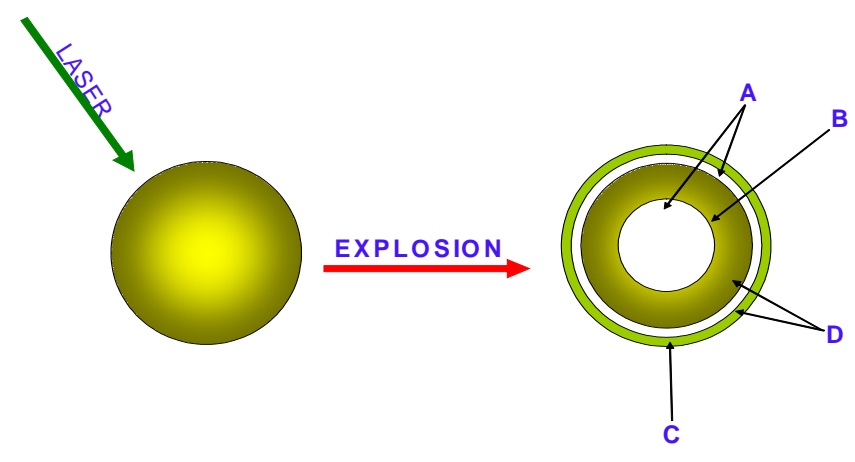

Fig. 2. Schematic presentation of the laser induced explosion of GNPs for the treatment of cancer.

A Areas of thermo mechanical damage.

B Au atoms and clusters with high velocity.

C Shock waves with supersonic expansion.

D High pressure layers.

treatment of various illnesses, especially in the targeting of cytotoxic drugs and radio nucleotides to diseased cells in the human body. However, the use of monoclonal antibodies presents limitations related to their immunogenicity and targeting specifics. Photodynamic therapy (PDT) is another type of treatment, in which cancer cells are destroyed using light activated dyes. When dye-loaded cells are treated with a laser, the dye interacts with oxygen to produce singlet state oxygen, which is highly toxic to cells. However, residual dye molecules can migrate to other normal tissues such as the skin and eyes, resulting in sensitivity to daylight (Salata 2004, El-Sayed et al. 2006).

Recently the use of gold colloids and GNPs has become an attractive platform in biomedical applications. GNPs have had a great impact on the medical community, are used for cancer diagnosis treatment, and as drug delivery vectors for biologic or pharmacological agents (Hirsch et al. 2005, Huang 2006, Niidome et al. 2006, Ding et al. 2007, Mukherjee et al. 2007). Biomedical applications of plasmon resonant metal nanoparticles were reported by Liao et al. (2006). The use of GNPs as drug carriers in diagnostic and medical fields is based on certain specific qualities such as: 1 ) they are easily fabricated and 2) the binding capacities of molecules with GNPs to target cancer cells, antibodies, carbohydrates and pharmacological agents, is higher than other nanoparticles (Hirsch et al. 2005, Huang 2006, Niidome et al. 2006, Mukherjee et al. 2007, Ganon et al. 2008). An illustration of the use of GNPs as drug carriers is shown in Fig. 3. 


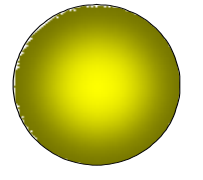

Nanogold
Drug-loaded nanogold

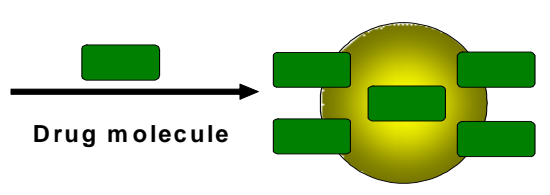

Fig. 3. Schematic illustration of nanogold used as a drug carrier for drug delivery.

GNPs have been used also as effective gene delivery vectors for the efficient transfection of DNA into the nucleus by tuning the surface charge density of aminoacid-functionalized GNPs. Transfection is the process of introducing nucleic acids into cells by non-viral methods. Transfection of animal cells involves opening transient pores or 'holes' in the cell plasma membrane, to allow the uptake of material. Genetic material (supercoiled plasmid DNA or siRNA constructs), or proteins such as antibodies, may be transfected into the cell plasma membrane. Ghosh et al. (2008) functionalized aminoacid-conjugated thiols with 1-pentaanethiol-protected gold clusters $\left(\mathrm{Au}-\mathrm{C}_{5}\right.$, core diameter $\sim 2 \mathrm{~nm}$ ). The functional head group transfection efficacy was explored using three different vectors (GNP-LysG ${ }_{1}$, GNP-Lys, and GNP-Gly) with differing densities of cationic sites. Aminoacid-functionalized gold colloids provide a scaffold for effective DNA binding with consequent condensation. The research concluded that particles functionalized especially with lysine and lysine dendron formed compact complexes and that gene delivery efficiency was high without any observable cytotoxicity. GNPs functionalized with first generation lysine dendrons (GNP-LysG1) showed $\sim 28$-fold greater efficacy than polylysine in reporter gene expression (Ghosh et al. 2008).

Multiple drug therapy has been proven to be an efficient treatment for complex diseases, but the difference in chemical properties and pharmacokinetics of different drugs causes serious concerns in terms of loading, delivering, and releasing multiple drugs. Wijaya et al. (2009) demonstrated the load and selective release of two different DNA oligonucleotides from two different gold nanorods, where DNA was loaded on the gold nanorods via thiol-conjugation. Ultra fast laser irradiation was used at the nanorods' longitudinal surface plasmon resonance peaks to melt gold nanorods for selective release. This particular type of gold nanorod can be selectively melted by the excitation at one specific wavelength after which it selectively releases one type of DNA strand. The release of DNAs was laser fluence tunable and its efficacy was 50-80\%. Released oligonucleotides were still functional (Wijaya et al. 2009).

\section{GNPs enhance gene regulation}

Small interfering RNA (siRNA), also known as silencing RNA, is a class of 20-25 nucleotide-long double-stranded RNA molecules which is involved in the RNA interference (RNAi) pathway, where it interferes with the expression of a specific gene. GNPs can be used as a shield to protect siRNAs from degradation and they can enhance the regulation of genes involved in cancer. Consequently, this straightforward method is receiving significant attention for the delivery of potent gene-regulating agents into targeted cells.

The therapeutic use of siRNA molecules has faced a number of problems among which is the degradation of siRNA molecules in the presence of the nucleases. These potentially therapeutic siRNA molecules are highly unstable, particularly if trace levels of enzymes called nucleases that break down nucleic acids are present. GNPs have been examined to avoid the degradation of siRNA molecules. For this examination, Giljohann et al. (2009) used a harsh stripping method to ensure that the surface of the GNPs was free of any nucleases. Surprisingly, this treatment did not have any effect on the optical or physical properties of the nanoparticles. Without the application of this pre-treatment, it was not possible to add any RNA molecules to nanoparticles. Using their developed pre-treatment, the resulting 13-nanometer GNPs held an average of 34 siRNA molecules each. In the confocal microscopical examination, the entry of nanoparticles into cultured tumour cells was also visible and inside the cell the siRNA was able to escape from the nanoparticle surface and inactivate its gene target. The efficacy of gene silencing achieved with the siRNA-nanoparticle construct was double compared with cells which were treated with siRNA alone. In conclusion, a boost in therapeutic efficacy arises because of improved siRNA stability when associated with GNPs.

\section{DNA-FUNCTIONALIZED GNPs IN TOXIC METAL DETECTION}

The application of GNPs to the detection of toxic metals such as mercury in the human body and in the 
environment (rivers, streams, lakes and oceans) represents a new goal. Industrial pollution caused by the release of many potentially toxic metals into the environment is a major world problem. Methyl mercury, a potential neurotoxin, is dangerous to young children and pregnant women when ingested in for example methyl mercury-contaminated fish or shellfish.

Lee et al. (2007) reported a novel colorimetric method which is sensitive, accurate, and capable of detecting mercury ions at 100 nanomolar level in aqueous samples. This is a procedure for monitoring mercury levels in lakes and rivers which is instrument free, highly selective for GNPs and, unlike other $\mathrm{Hg}^{2+}$ detection methods, does not require organic solvents or co-solvents. GNPs-DNA conjugates exhibit a purple colour, as they are held with oligonucleotides at a critical distance. The key to the method is that a purple to red colour change occurs at $46{ }^{\circ} \mathrm{C}$ if the solution has no mercury, and occurs at a higher temperature if mercury is present. Mercury binds strongly to the T-T mismatch site and the GNPs are now held together even more tightly. The mercury creates a stronger bond that requires a higher temperature to break apart the DNA strands and exhibit the purple colour. When we heat this solution above $46{ }^{\circ} \mathrm{C}$, DNA strands will automatically be separated and the GNPs are no longer in close proximity to each other. The colour turns to to bright red, indicating how much mercury is present at the high temperature.

Based on previous knowledge of the capacity of mercury to bind to the bases of thymidine-thymidine (T-T) mismatch, Lee et al. (2007) designated each strand of DNA containing thymidine-thymidine mismatchto be attached to GNPs. If there is mercury in the test solution, then it is tightly bounded to thymidine-thymidine mismatch.

So, in the test solution, the detection of mercury ion traces can be made easily by following the changes in the colour of the solution from purple to bright red. This method is selective for $\mathrm{Hg}^{2+}$ and insensitive to $\mathrm{Mg}^{2+}, \mathrm{Pb}^{2+}, \mathrm{Cd}^{2+}, \mathrm{Co}^{2+}, \mathrm{Zn}^{2+}, \mathrm{Ni}^{2+}$, and other metal ions.

Recently scientific results reveal that GNPs can be used to trap toxins, bacteria, viruses used by bioterrorists. GNPs act as very effective detectors of biological toxins. Solutions of the GNPs are a strong red colour but instantly they change to blue when the target substance is present. The particles reveal the presence of toxins faster and with a detection limit lower than existing techniques (http://news.bbc.co.uk/2/hi/technology/4872188.stm, viewed on $18^{\text {th }}$ February 2009).

\section{OTHER MEDICAL APPLICATIONS}

\section{GNPs in DNA detection}

Nanotechnology is achieving better results in all research areas related to/and connected with DNA detection - sensitivity, selectivity, ease of use, cost and speed. Park et al. (2002) developed a novel DNA detection technique by using gold nanoprobes. The technique is more accurate, less expensive and faster than conventional methods. The technique applied a simple electrical signal for the detection of target DNA. These new DNA detection techniques replace classical DNA detection techniques such as for example, the polymerase chain reaction (PCR), using conventional fluorescent probes in clinical diagnostics. Different DNA samples can be placed on a glass slide. Each sample is made up of single strands of synthesized DNA or oligonucleotides, with a sequence designed to bind with its complimentary target DNA. These oligonucleotides are then placed between a pair of electrodes. The gold nanoparticle probes, each covered with oligonucleotide strands, latch on to these pairings. Only perfect matches will remain, and this allows silver-coated-gold nanoprobes to carry a measurable electrical signal across the gap between the electrodes. The detection limit of the target DNA is 500 femtomolar concentrations and a point mutation selectivity factor of $100,000: 1$ was feasible by this method (Park et al. 2002). This methodology may be applied to the detection of hundreds of pathogenic agents, simultaneously. After optimization, the method may be used to quickly and easily detect biological weapons such as anthrax, and small pox and also to diagnose many pathogenic and genetic diseases, cancer, HIV and other sexually transmitted diseases. Obtaining results would take only a matter of minutes instead of days (Park et al. 2002).

The development and application of hybrid materials which include the conjugation of inorganic nanoparticles, such as GNPs with biomolecules (i.e. proteins, polynucleotides), have been reported by Dubertret et al. (2001). A 25-base synthetic oligonucleotide modified with primary amine at its 3 ' end and a disulfide at its 5 ' end was selected for the experiment. This oligonucleotide acquires a hairpin-loop structure as its extremities. The pattern of sequence provides a hairpin-loop structure which is very stable at room temperature. The combination of the highly specific properties of biomolecules with the unique optical properties of nanoparticles, make them highly suitable for use in the field of biodiagnostics. Dubertret et al. (2001) demonstrated that high sensitivity is reached when hybrid 
dye-DNA-nanoparticle materials such as nucleic acid probes to detect specific nucleotide sequences are applied. The structure of the synthetic oligonucleotide opens easily on hybridization of the loop to its target. Initially, an amine reactive dye was conjugated to the primary amine at the 3' end of the oligonucleotide. Disulfide at the 5' end of the oligonucleotide was cleaved after purification and free sulfhydryl was covalently attached to $1.4 \mathrm{~nm}$ diameter gold cluster. This hairpin structure, with a gold nanoparticle at one end and fluorescent dye at the other end presents a strongly suppressed fluorescence. When present in solution of specific strands of DNA, the linker is unzipped, and the dye begins to shine as much as 1000 times brighter than before (Fig. 4).

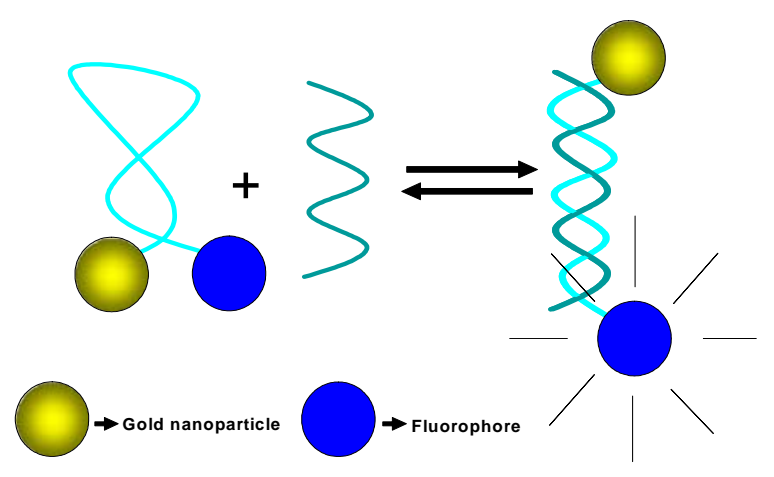

Fig. 4. Hybrid dye-DNA-nanoparticle materials can be used as nucleic acid probes to detect specific nucleotide sequences with incredible sensitivity.

The newly developed GNP-DNA nanoconjugates are used to measure the nuclease activity and for DNA foot printing (Liu et al. 2006) (Fig. 5A, B).

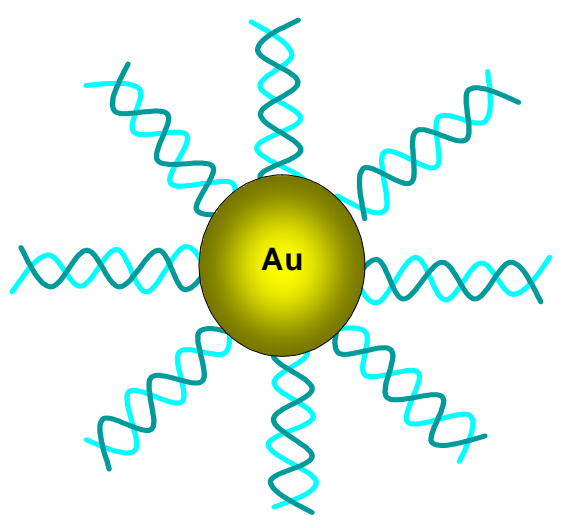

Fig. 5A. DNA conjugate with a single GNP.

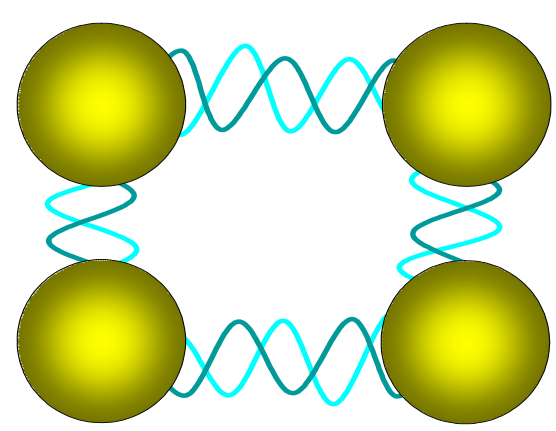

Fig. 5B. GNP-DNA nanoconjugate for measuring nuclease activity and DNA footprinting.

\section{GNPs in bioimaging}

Optical imaging is a technique which encompasses the elucidation of morphology, molecular function, and metabolism of tissue. GNPs have intense plasmon resonance driven absorption and scattering properties. The plasmon resonance condition of GNPs depends on their size, shape, structure, and refractive index of the embedding medium. Due to these special properties, they are used as contrast agents for optical imaging techniques. Cellular imaging using gold nanorods was also reported recently by Murphy et al. (2008). Rayavarapu et al. (2007) applied the bio-conjugated GNPs (nanospeheres, nanorods) for imaging, where the conjugation was achieved by using a combination of electrostatic and hydrophobic binding interactions. The particles selected for this conjugation were $25 \mathrm{~nm}$ citrate-capped gold spheres. Gold nanorods conjugated with HER81 antibodies bind with high efficiency to Her2 receptors expressed by SKBR3 breast carcinoma cells (Rayavarapu et al. 2007).

Using multifunctional GNPs, Kumar et al. (2007) described the intracellular molecular imaging platform. The multifunctional GNPs incorporating both cytosolic delivery and targeting moieties are named as "nanosensors". These nanosensors can be effectively delivered into the cytoplasm and bind to their target providing a strong molecular specific optical signal. For developing the nanosensors, monodisperse water soluble $20 \mathrm{~nm}$ GNPs and anti-actin and anti-biotin antibodies were used. The GNPs were attached to antibodies via a hetero functional linker that consisted of an alkaline terminating in a dithiol tether and an amide-bonded adipic hydrazide (Kumar et al. 2007). Finally, these nanosensors will bind strongly to the actin or biotin and give the optical signal (Fig. 6). 


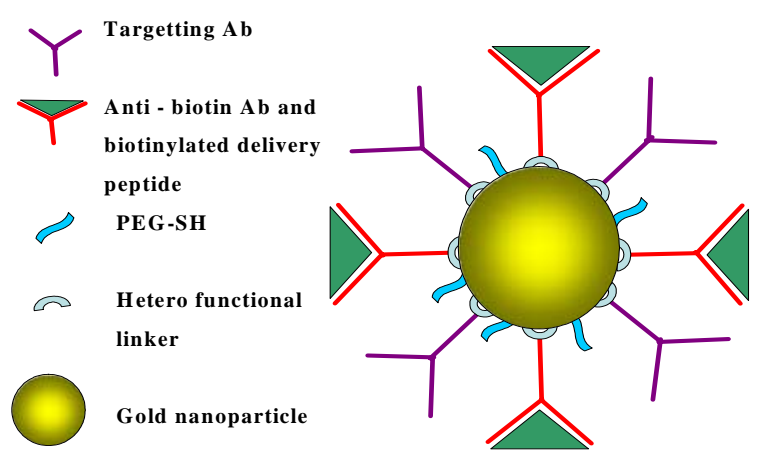

Fig. 6. Multifunctional plasmonic nanosensor for imaging intra-cellular biomarkers in live cells. A schematic representation of gold nanoparticle based nanosensor with both targeting and delivery components.

\section{GNPs in brain activity imaging}

The human brain is a complicated structure, consisting of trillions of interconnections between tens of billions of neurons. The aim of modern neuroscience is to develop creditable goals for the fundamental understanding of these circuits for neurological and general health care reasons. Metal nanoparticles, such as GNPs have a localized surface plasmon (LSP) resonance property and can be used for optical sensing. The optical properties of GNPs make them most significant as they can provide enhanced functionality for several biological applications. Some optical properties of star shaped GNPs have also been reported (Nehl et al. 2006). Due to their bright, stable scattering signal, GNPs are being used as labels for microscopic imaging. Lining up tiny electrodes within or near single neurons to probe their electrical activity is one of the ways to 'walk around' the brain's microcircuit system. Although it is a well established technique, it has some limitations due to it being an invasive method and noisy, because of the background electrical activity in the brain. Many techniques have been tried to investigate the neuronal structures of the brain, for example by using optical probes that can detect neuronal activity with light. However, these methods often require labelling neuronal cells with electrically sensitive dyes that may be toxic to neurons in human brain (Zhang et al. 2009). Avoiding the use of toxic dyes, a new type of dye-free optical probe, that can directly sense naturally occurring neural activity, was developed (Zhang et al. 2009). This methodology includes the embedding of GNPs into brain tissue cultures, followed by measurement of the electrical activity of live neurons. Zhang et al. (2009) reported the optical detection of brain cell activity by using plasmonic GNPs. An electrostatic field sensing technique has been used to detect mammalian brain cell activity, by optically measuring the cellular potential induced shift in the surface plasmon resonance mode of an adjacent planar gold nanoparticle array. Hippocampal brain neural cells were cultured onto the GNPs template. When the chemically triggered neurons switched their potential, optical cellular level individual transient signals were detected. The neuronal activity modulates the electron density at the surface of the nanoparticle, giving as a result, an observable spectral shift that can be monitored. Zhang et al. (2009) compared the experimental data with calculations using the Drude model for the dielectric response of gold and the Stern model for the metal-electrolyte junction and they were found to be in close agreement with theoretical calculations.

\section{GOLD QDs APPLICATIONS}

\section{Gold QDs in immuno assays}

During the last decade, fluorescence based assays have taken a priority position in immunochemistry-based in vitro diagnosis and in vivo imaging assays. There are a number of advantages in using radio chemical labels and chromophores: higher sensitivity, their potential for easy multiplexing, their optical properties, including narrow absorption band width, broad excitation, size dependent controllable emission spectra, high molar absorptivity and potential stability against photo bleaching, and it is thought that semiconductor QDs will replace the traditional organic or organometallic fluorophores. Triulzi et al. (2008) synthesized gold QDs using polyamidoamine (PAMAM) dendrimers as capping ligands. The gold QDs show size- dependent narrow emissions, narrow excitation and excellent biocompatibility and are suitable for biological applications. PAMAM dendrimers have proven to be excellent cell transfect ion agents due to the presence of hydroxyl or amine groups at their end groups. So, with the combination of a biologically inert material such as gold, along with biological compatibility, it penetrates to the cell membranes. This combination could be efficiently conjugated to various biomolecules as DNA, RNA, proteins and carbohydrates. PAMAM dendrimers can be covalently or electrostatically conjugated to DNA (Choi et al. 2004, 2005), RNA (Kang et al. 2005), carbohydrates (Tsvetkov et al. 2002) and proteins (Lee et al. 2004, Wang et al. 2007, Triulzi et al. 2008). 
Triulzi et al. (2008) reported the use of gold QDs in a human IgG immunoassay. The gold QDs were electrostatically conjugated to a goat-derived anti-human IgG polyclonal antibody to detect human IgG. The conjugate of gold QDs-PAMAM dendrimers-antibody complex was treated with specific antigens such as $\mathrm{IgG}$, rabbit $\mathrm{IgG}$, and a number of unrelated proteins such as bovine serum albumin and $\beta$-casein. Encapsulated gold QDs in PAMAM dendrimers with the combination of specific antigens like anti-human IgG were very stable. The different systems exhibited a linear luminescence quenching response over the micromolar to nanomolar human IgG concentration range with little or no interference from BSA or $\beta$-casein and a slight interference from rabbit $\mathrm{IgG}$, which indicated the specificity of anti-human IgG antibody. A strong influence of specific antigen (human IgG) concentration on the luminescence of gold QDs was observed and no influence was observed on BSA or $\beta$-casein. A linear decrease in the luminescence of the gold QDs was seen with an increase in the concentrations of human IgG over the range of concentration from micromolar to nanomolar. It followed that the mechanism of antibody-induced selectivity in competitive surface quenching is mainly dependent on the size of the quantum dots. This lends great credence to the usage of different varieties of ligand specific assays for diagnostics and imaging applications in nanomedicine (Triulzi et al. 2008).

Gold Quantum dots-Protease complexes as "smart nanoprobes" for disease detection

Imaging for the detection of diseases is a long standing problem in medicine. The use of GNP-based nanostructures allows 'illumination' of the disease location, making it possible to distinguish between the signals due to "cancer is here", and so called 'background' light (arising from nanostructures not specifically bound to their molecular targets). Actually, QDs make it possible to solve this problem. Emissive nanoparticles as QDs exhibit a unique property: they give off light in the near-infrared, a rare portion of the spectrum that has no background components in biomedical imaging. Near-infrared light also passes harmlessly through muscle, cartilage and skin. So these new QDs probes can alert researchers to tumours and other diseases localized deeply in the human body. There is no need for a biopsy and/or invasive surgery to detect the locations of these diseases. The 'smart nanoprobes' developed consist of gold tethered quantum dots, which are a hundred times smaller than a human cell and areas programmed to light up when they are activated by specific proteases. This altered expression of specific proteases is a hallmark of cancer, arthrosclerosis and many other diseases (Chang et al. 2005).

The major mechanism in the construction of these 'smart nanoprobes' is the use of QDs which have a unique property of luminescence. These probes are prepared by a special technique called "quenching". Quenching involves binding a gold nanoparticle to the quantum dot to inhibit its luminescence. These QD-peptide-GNPs are used for detection of proteolytic activity proteases. When a specific protease cleaves peptide in the QD-peptide-GNPs complex, the GNPs are released and these GNPs exhibits luminescence, and by following this luminescence, the exact disease location can be found (Chang et al. 2005).

\section{GOLD AND GNPs TOXICITY}

Although gold and gold compounds have been used as a potential drug for the treatment of RA, some adverse effects, such as skin irritation, dermatosis, stomatitis, contact allergy, and hypersensitivity reactions were associated with over exposure to gold and gold compounds.

Gold compounds such as gold sodium thio sulphate (GSTS) have been used as a dental gold alloy. Vamnes et al. (2000) reported two critical cases of the adverse effects of dental gold alloys. In the first case study, a healthy 34-year-old woman was affected by dental gold and demonstrated symptoms which included itching in the mouth, loss of taste, and burning sensation in the oral mucosa. Non-specific dermatitis was also observed on her face. Her symptoms persisted and increased over some months (Vamnes et al. 2000). In the second case study described by Vamnes et al. (2000), a healthy 50year-old man was affected by the wearing of a gold-containing crown; the symptoms were itchy lichenoid dermatitis, which was symmetrically distributed on the trunk and thighs.

According to McKenna et al. (1995), 278 consecutive patients with suspected contact dermatitis were patch tested with GSTS. Around 13 patients $(4.6 \%)$ were affected with a positive allergic response. The patients were female, with an average age of 37 years. The most affected sites of eczema (generic term for inflammatory conditions of the skin) were head and neck (62\%); $46 \%$ of people had eczema on the limbs and $15 \%$ had a perianal rash.

Räsänen et al. (1999) examined the hypersensitivity reactions involved in dermatosis induced by gold sodium thiomalate (GSTM). 
Svensson et al. (2002) examined the clinical and biochemical effects of a low starting dose for gold therapy in RA patients with a contact allergy to gold. Four out of 19 patients were found to be affected by contact allergy to gold. In comparison with the gold-negative patients (starting dose: $10 \mathrm{mg} \mathrm{GSTM}$ ), a large increase of TNF- $\alpha$, sTNF-R1, IL-1 ra (interleukin-1 receptor antagonist) was observed in the serum of gold-allergic patients. Räsänen et al. (1999) concluded that it is better to minimize the dose of GSTM to $5 \mathrm{mg}$ to reduce the risk of adverse reactions. Fleming et al. (1997) examined 8 patients to detect gold contact hypersensitivity. Two out of eight patients were shown to be positive to gold allergy which is mainly caused by wearing gold jewellery.

\section{GNPs cytotoxicity}

Nanoscale engineering is one of the most attractive technologies and includes knowledge of various fields such as electronics, physics, biology and medicine. However the use of nanoparticles could be limited because of toxic effects on health. (Lewinski et al. 2007). It has recently been reported that silver nanoparticles can have hazardous effects on human health and the environment (Panyala et al. 2008). GNPs also represent some hazardous effects on human health. The few papers which have been published on the cytotoxicity of GNPs are referred to in the following discussion.

According to Pan et al. (2007) the cytotoxicity of GNPs was checked by including them with various incubating cell lines; for example, HeLa cervix carcinoma epithelial cells (HeLa), SK-Mel-28 melanoma cells (SK-Mel-28), L929 mouse fibroblasts (L929) and mouse monocytic/macrophage cells. It was observed in transmission electron microscopical studies that the cells were swollen and lost their substrate contact. Membrane blebbing and vesicle formation at the plasma membrane were observed. After 12 hours incubation with GNPs, many cells had lost cell-to-cell and cell-to-substrate contact. A few cells showed cytoplasmic disintegration, membrane blebbing and nuclear fragmentation indicating apoptosis and secondary necrosis. Pan et al. (2007) described the cell death by gold clusters in the cell lines, finding two types of cell death in the cell lines. Firstly, there is a rapid cell necrosis caused by strong physical stress, such as freezing, boiling, shearing, and rupture of the cell membrane. The products released by this necrosis process are also highly inflammatory so they can cause inflammation in the human body. The second type of cell death - slow acting cell death - also called apoptosis, doesn't involve membrane damage and inflammation. In this apoptosis or programmed cell death, cells undergo an energy-dependent sequence of events, which leads to the fragmentation of nuclei and cytoplasmic organelles into small apoptotic bodies eliminated by phagocytes. Apoptosis is a default process in which destroyed particles and dead cells are scavenged by the macrophages in our body (Pan et al. 2007).

Connor et al. (2005) examined the GNPs uptake into human cell lines and their cytotoxic levels by culturing K562 human leukaemia. As a result it was concluded that GNPs and functionalized GNPs have no potential toxic effects on human leukaemia cell lines. Moreover, the results confirmed that a few functionalized GNPs such as CTAB (cetyltrimethylammonium bromide)-modified GNPs have potential toxic effects on human cell lines. CTAB also shows toxicity in human cell lines. Goodman et al. (2004) reported cationic and anionic functionalized GNP toxicity and they concluded that cationic functionalized GNPs have moderate toxicity when compared with anionic functionalized GNPs.

Pernodet et al. (2006) examined the adverse effects of citrate coated GNPs on human dermal fibroblast cells. The presence of GNPs led to major changes in cell growth, cell shape and alteration of actin fibres. It was shown that $14 \mathrm{~nm}$ GNPs can easily pass through the cell membrane and accumulate into vacuoles. The presence of GNPs is responsible for abnormal actin filaments and extra cellular matrix constructs in dermal fibroblasts. It leads to a decrease in cell proliferation, adhesion and motility.

Wiwanitkit et al. (2009) examined the in vitro toxic effects of $9 \mathrm{~nm}$ size GNPs on the human spermatozoa. A fresh semen sample was cultured with $500 \mu \mathrm{L}$ of GNPs and motility and morphological changes were studied after 15 minutes by clinical microscopy. The same changes were studied as well for the blank sample which was not cultured with the GNPs. Microscopic examinations revealed that $25 \%$ of sperm cells were not motile and penetration of GNPs into the sperm head and tail was observed. In addition, the fragmentation of the sperm was visible.

Cho et al. (2009) studied the in vivo toxic effects of $13 \mathrm{~nm}$ size PEG-coated GNPs on mice. The nanoparticles were seen to induce acute inflammation and apoptosis in the liver. They accumulated in the liver and spleen for up to 7 days after injection and had long blood circulation times. In addition, transmission electron microscopical examinations revealed that numerous cytoplasmic vesicles and lysosomes of liver Kupffer cells and spleen macrophages contained the PEG-coated gold nanoparticles. Because PEG-coated GNPs are widely used in biomedical applications these effects have obvious clinical implications. 
Chen et al. (2009) also studied the in vivo toxicity of GNPs on mice. Naked GNPs ranging from 3 to 100 $\mathrm{nm}$ were injected intraperitoneally into mice at a dose of $8 \mathrm{mg} / \mathrm{kg} /$ week. GNPs of 3, 5, 50, and $100 \mathrm{~nm}$ did not show any toxic effects; however, GNPs ranging from 8 to $37 \mathrm{~nm}$ induced severe sickness in mice and mice injected with GNPs in this range showed fatigue, change of fur colour, loss of appetite, and weight loss.

\section{DISCUSSION AND CONCLUSIONS}

From ancient time, gold and gold compounds have been used as a medication as it was believed that gold has the power to cure a number of diseases, among them rheumatoid arthritis. Recent developments in nano-science have also made a number of application based upon the use of nano-materials available to medicine. The most important of these materials for 'nanomedicine' is nano-gold.

GNPs show entirely different properties in comparison with their bulk counterparts. GNPs have a capability of binding strongly to bio molecules like proteins, peptides, antibodies, oligonucleotides, and pathogens such as bacteria, viruses, etc. GNPs could be used as biomarkers to detect diseases and to deliver a suitable drug to cure the disease. However, even though gold and gold salts such as auranofin, aurothioglucose have been used as active medicine in the treatment of, for example, RA they could have toxic effects on human health.

The use of functionalized GNPs as biomarkers and their binding capacity to biomolecules is opening new feasibilities, for example, attenuation of the function of the disease causing proteins. Much concern is paid to the investigation of GNP interaction studies such as type of binding, structure of biomolecules, and influence of charge on the interaction. The interaction of biomolecules with GNPs needs to be even more deeply investigated. There are still many problems and questions to be answered. For example, is interaction of biomolecules with GNPs a size dependent process or are there other factors influencing the interaction? Are we able to design GNPs that will attenuate the function of disease causing proteins with more efficiency and more specificity? There are many questions similar to these.

It is shown in the literature that there are a number of potential adverse effects of gold and GNPs on human health. It is evident that the toxic and cytotoxic effects of GNPs have not been sufficiently investigated to date, and a critical examination is needed of GNP cytotoxicity and the symptoms of over-exposure to GNPs. Also it is necessary to investigate the feasibilities of minimizing the cytotoxic levels of GNPs to use them in various biomedical applications without any hazardous effects on human health. The design of less toxic and therapeutically significant GNPs might open new ways of approaching incurable diseases. Generally, the use of gold and GNPs applications in medicine is growing so rapidly that great progress and perhaps surprising new developments can be expected in the near future.

\section{ACKNOWLEDGEMENTS}

Support from the Ministry of Education, Youth and Sports of the Czech Republic, projects MSM0021622411 and LC 06035 and Academy of Sciences of the Czech Republic, project KAN 101630651 are greatly acknowledged. E.M.P-M and J.H. acknowledge the partial support from University of La Laguna, La Laguna, Tenerife, Spain.

\section{REFERENCES}

Bernhard GC: Auranofin therapy in rheumatoid arthritis. J Lab Clin Med 100:167-177, 1982.

Bhattacharya R, Patra CR, Earl A, Wang S, Katarya A, Beng LL, Kizhakkedathu JN, Yaszemski MJ, Greipp PR, Mukhopadhyay D, Mukherjee P: Attaching folic acid on gold nanoparticles using noncovalent interaction via different polyethylene glycol backbones and targeting of cancer cells. Nanomed Nanotechnol Biol Med 3:224-238, 2007.

Bhattacharya R, Mukherjee P: Biological properties of "naked" metal nanoparticles. Adv Drug Deliv Rev 60:1289-1306, 2008.

Bilchik AJ, Wood TF, Allegra D, Tsioulias GJ, Chung M, Rose DM, Ramming KP, Morton DL: Cryosurgical ablation and radiofrequency ablation for unrespectable hepatic malignant neoplasms: a proposed algorithm. Arch Surg 135:657-662, 2000.

Bleicher RJ, Allegra DP, Nora DT, Wood TF, Foshag LJ, Bilchik AJ: Radiofrequency ablation in 447 complex unrespectable liver tumours: lessons learned. Ann Surg Oncol 10:52-58, 2003.

Brigger I, Dubernet C, Couvreur P: Nanoparticles in cancer therapy and diagnosis. Adv Drug Deliv Rev 54:631-651, 2002. 
Bruchez MJ, Maronne M, Gin P, Weiss S, Alivasatos AP: Semiconductor nanocrystals as fluorescent biological labels. Science 281:2013-2016, 1998.

Cai W, Gao T, Hong H, Sun J: Applications of gold nanoparticles in cancer nanotechnology. Nanotechnol Sci Appl 1:17-32, 2008.

Chaffman M, Brogden RN, Heel RC, Speight TM, Avery GS: Auranofin. A preliminary review of its pharmacological properties and therapeutic use in rheumatoid arthritis. Drugs 27:378-424, 1984.

Chan WCW, Nie S: Quantum dot bioconjugates for ultrasensitive nonisotopic detection. Science 281:2016-2018, 1998.

Chan WCW, Maxwell DJ, Gao X, Bailey RE, Han M, Nie S: Luminescent quantum dots for multiplexed biological detection and imaging. Curr Opin Biotechnol 13:40-46, 2002.

Chang E, Millar JS, Sun J, Yu WW, Colvin VL, Drezek R, West JL: Protease-activated quantum dot probes. Biochem Biophys Res Commun 334:1317-1321, 2005.

Chen J, Wang D, Xi J, Au L, Siekkinen A, Warsen A, Li Zhi-Yuan, Zhang H, Xia Y, Li X: Immuno gold nanocages with tailored optical properties for targeted photo thermal destruction of cancer cells. Nano Lett 7:1318-1322, 2007.

Chen YS, Hung YC, Liau I, Huang GS: Assessment of the in vivo toxicity of gold nanoparticles. Nanoscale Res Lett, 2009, in press.

Chithrani BD, Ghazani AA, Chan WCW: Determining the size and shape dependence of gold nanoparticle uptake into mammalian cells. Nano Lett 6:662-668, 2006.

Cho WS, Cho M, Jeong J, Choi M, Cho HY, Han BS, Kim SH, Kim HO, Limc YT, Chung BH, Jeong J: Acute toxicity and pharmacokinetics of 13 nm-sized PEG-coated gold nanoparticles. Toxicol Appl Pharmacol 236:16-24, 2009.

Choi Y, Mecke A, Orr BG, Holl MMB, Baker JR Jr.: DNA-directed synthesis of generation 7 and 5 PAMAM dendrimer nanoclusters. Nano Lett 4:391-397, 2004.

Choi Y, Thomas T, Kotlyar A, Islam MT, Baker JR: Synthesis and functional evaluation of DNA-assembled polyamidoamine dendrimer clusters for cancer cell-specific targeting. Chem Biol 12:35-43, 2005.

Connor EE, Mwamuka J, Gole A, Murphy CJ, Wyatt MD: GNPs are taken up by human cells but do not cause acute cytotoxicity. Small 1:325-327, 2005.

Cuenca AG, Jiang H, Hochwald SN, Delano M, Cance WG, Grobmyer SR: Emerging implications of nanotechnology on cancer diagnostics and therapeutics. Cancer 107:459-466, 2006.
Curley SA, Marra P, Beaty K, Ellis LM, Vauthey JN, Abdalla EK, Scaife C, Raut C, Wolff R, Choi H, Loyer E, Vallone $\mathrm{P}$ et al.: Early and late complications after radiofrequency ablation of malignant liver tumours in 608 patients. Ann Surg 239:450-458, 2004.

Daniel MC, Astruc D: GNPs: assembly, supramolecular chemistry, quantum-size related properties, and applications toward biology, catalysis, and nanotechnology. Chem Rev 104:293-346, 2004.

Davis P: Gold therapy in the treatment of rheumatoid arthritis. Can Fam Physician 34:445-452, 1988.

Ding Y, Liu J, Wang H, Shen G, Yu R: A piezoelectric immunosensor for the detection of $\alpha$-fetoprotein using an interface of gold/hydroxyapatite hybrid nanomaterial. Biomaterials 28:2147-2154, 2007.

Dobrovolskaia MA, Patri AK, Zheng J, Clogston JD, Ayub N, Aggarwal P, Neun BW, Hall JB, McNeil SE: Interaction of colloidal gold nanoparticles with human blood: effects on particle size and analysis of plasma protein binding profiles. Nanomed Nanotechnol Biol Med, 2009, in press.

Dubertret B, Calame M, Libchaber AJ: Single-mismatch detection using gold-quenched fluorescent oligonucleotides. Nat Biotechnol 19:365-370, 2001

El-Sayed IH, Huang X, El-Sayed MA: Selective laser photo-thermal therapy of epithelial carcinoma using anti-EGFR antibody conjugated GNPs. Cancer Lett 239:129-135, 2006.

Faulk W, Taylor G: An immunocolloid method for the electron microscopy. Immunochemistry 8:1081-1083, 1979.

Felson DT, Anderson JJ, Meenan RF: The comparative efficacy and toxicity of second-line drugs in rheumatoid arthritis. Results of two metaanalyses. Arthritis Rheum 33:1449-1461, 1990.

Fleming C, Forsyth A, Mackie R: Prevalence of gold contact hypersensitivity in the west of Scotland. Contact dermatitis 36:302-304, 1997.

Forestier J: Rheumatoid arthritis and its treatment by gold salts. J Lab Clin Med 20:827-40, 1935.

Fricker SP, Buckley RG: Comparison of two colorimetric assays as cytotoxicity endpoints for an in vitro screen for antitumour agents. Anticancer Res 16:3755-3760, 1996.

Gannon CJ, Curley SA: The role of focal liver ablation in the treatment of unrespectable primary and secondary malignant liver tumours. Semin Radiat Oncol 15:265-272, 2005.

Gannon CJ, Patra CR, Bhattacharya R, Mukherjee P, Curley SA: Intracellular GNPs enhance 
non-invasive radiofrequency thermal destruction of human gastrointestinal cancer cells. J Nanobiotechnol 6:2-10, 2008.

Ghosh PS, Kim Chae-Kyu, Han G, Forbes NS, Rotello VM: Efficient gene delivery vectors by tuning the surface charge density of aminoacid-functionalized GNPs. ACS Nano 2:2213-2218, 2008.

Giljohann DA, Seferos DS, Prigodich AE, Patel PC, Mirkin CA: Gene regulation with polyvalent siRNA-nanoparticle conjugates. J Amer Chem Soc 131:2072-2073, 2009.

Glennås A, Kvien TK, Andrup O, Clarke-Jenssen O, Karstensen B, Brodin U: Auranofin is safe and superior to placebo in elderly-onset rheumatoid arthritis. Br J Rheumatol 36:870-877, 1997.

Goodman CM, McCusker CD, Yilmaz T, Rotello VM: Toxicity of GNPs functionalized with cationic and anionic side chains. Bioconjugate Chem 15:897-900, 2004.

Haemmerich D, Laeseke PF: Thermal tumour ablation: Devices, clinical applications and future directions. Int J Hyperthermia 21:755-760, 2005.

Hirsch LR, Halas NJ, West JL: Whole-blood immunoassay facilitated by gold nanoshell-conjugate antibodies. Methods Mol Biol 303:101-111, 2005.

Houška $\mathrm{J}$, Alberti $\mathrm{M}$, Havel $\mathrm{J}$ : Laser ablation synthesis of phosphorus sulphides, selenides and ternary $\mathrm{P}_{\mathrm{p}} \mathrm{S}_{\mathrm{q}} \mathrm{Se}_{\mathrm{r}}$ clusters from various precursors. Rapid Commun Mass Spectrom 22:417-423, 2008.

Houška J, Panyala NR, Peña-Méndez EM, Havel J: Mass spectrometry of nanodiamonds. Rapid Commun Mass Spectrom 23:1125-1131, 2009a.

Houška J, Peña-Méndez EM, Kolář J, Frumar M, Wágner T, Havel J: Laser ablation of AgSbS2 and cluster analysis by time-of-flight mass spectrometry. Rapid Commun Mass Spectrom 23:1715-1718, 2009b.

Huang SH: Gold nanoparticle-based immunochromatographic test for identification of Staphylococcus aureus from clinical specimens. Clin Chim Acta 373:139-143, 2006.

Jain KK: Nanotechnology-based drug delivery for cancer. Technol Cancer Res Treat 4:407-416, 2005.

Juzenas P, Chen W, Sun YP, Coelho MAN, Generalov R, Generalova N, Christensen IL: Quantum dots and nanoparticles for photodynamic and radiation therapies of cancer. Adv Drug Deliv Rev 60:1600-1614, 2008.

Kam NW, Liu Z, Dai H: Carbon nanotubes as intracellular transporters for proteins and DNA: an investigation of the uptake mechanism and pathway. Angew Chem Int Edn Engl 45:577-581, 2006.

Kang $\mathrm{H}$, DeLong R, Fisher $\mathrm{MH}$, Juliano RL: Tat-conjugated PAMAM dendrimers as delivery agents for antisense and siRNA oligonucleotides. Pharm Res 22:2099-2106, 2005.

Krasovskii VI, Nagovitsyn IA, Chudinova GK, Savranskii VV, Karavanskii VA: Interaction of gold nanoparticles with bovine serum albumin. Bull Lebedev Phys Inst 34:321-324, 2007.

Kumar S, Harrison N, Richards-Kortum R, Sokolov $\mathrm{K}$ : Plasmonic nanosensors for imaging intracellular biomarkers in live cells. Nano Lett 7:1338-1343, 2007.

Landé K: Die gunstige, Heinflussing schleichender Dauerinfectionen surch Solganal. Munch Med Wchschr 74:1132-1139, 1927.

Lee JS, Han MS, Mirkin CA: Colorimetric Detection of Mercuric Ion $\left(\mathrm{Hg}^{2+}\right)$ in Aqueous Media using DNA Functionalized GNPs. Angew Chem 46:4093-4096, 2007.

Lee SC, Parthasarathy R, Botwin K, Kunneman D, Rowold E, Lange G, Klover J, Abegg A, Zobel J, Beck T, Miller T, Hood W et al.: Biochemical and immunological properties of cytokines conjugated to dendritic polymers. Biomed microdevices 6:191-202, 2004.

Letfullin RR, Joenathan C, George TF, Zharov VP: Laser induced explosion of gold nanoparticles: potential role for nanophotothermolysis of cancer. Nanomedicine 1:473-480, 2006.

Lewinski N, Colvin V, Drezek R: Cytotoxicity of nanoparticles. Small 4:26-49, 2007.

Liao H, Nehl CL, Hafner JH: Biomedical applications of plasmon resonant metal nanoparticles. Nanomedicine 1:201-208, 2006.

Liu GL, Yin Y, Kunchakarra S, Mukherjee B, Gerion D, Jett SD, Bear DG, Gray JW, Alivisatos AP, Lee LP, Chen FF: A nanoplasmonic molecular ruler for measuring nuclease activity and DNA footprinting. Nat Nanotechnol 1:47-52, 2006.

Lu W, Xiong C, Zhang G, Huang Q, Zhang R, Zhang JZ, Li C: Targeted photo thermal ablation of murine melanomas with melanocyte-stimulating hormone analog-conjugated hollow gold nanospheres. Clin Cancer Res 15:876-886, 2009.

Mahdihassan S: Colloidal gold as an alchemical preparation. Janus 58:112-118, 1971.

Mahdihassan S: The tradition of alchemy in India. Am J Chin Med 9:23-33, 1981.

Mahdihassan S: Cinnabar-gold as the best alchemical drug of longevity, called Makaradhwaja in India. Am J Chin Med 13:93-108, 1985.

McKenna KE, Dolan O, Walsh MY, Burrows D: 
Contact allergy to gold sodium thiosulfate. Contact dermatitis 32:143-146, 1995.

Moghimi SM, Hunter AC, Murray JC: Nanomedicine: Current status and future prospects. FASEB J 19:311-330, 2005.

Mukherjee P, Bhattacharya R, Wang P, Wang L, Basu S, Nagy JA, Atala A, Mukhopadhyay D, Soker S: Antiangiogenic properties of GNPs. Clin Cancer Res 11:3530-3534, 2005.

Mukherjee P, Bhattacharya R, Bone N, Lee YK, Patra CR, Wang S, Lu L, Charla S, Banerjee PC, Yaszemski MJ, Kay NE, Mukhopadhyay D: Potential therapeutic application of GNPs in B-chronic lymphocytic leukaemia (BCLL): enhancing apoptosis. J Nanobiotechnol 5:4, 2007.

Murphy CJ, Gole AM, Stone JW, Sisco PN, Alkilany AM, Goldsmith EC, Baxter SC: GNPs in biology: Beyond toxicity to cellular imaging. Acc Chem Res 41:1721-1730, 2008.

Nehl CL, Liao H, Hafner JH: Optical properties of star-shaped GNPs. Nano Lett 6:683-688, 2006.

Nehl CL, Hafner JH: Shape-dependent plasmon resonances of gold nanoparticles. J Mater Chem 18:2415-2419, 2008.

Niidome T, Yamagata M, Okamoto Y, Akiyama Y, Takahashi H, Kawano T, Katayama Y, Niidome Y: PEG-modified gold nanorods with a stealth character for in vivo applications. J Control Release 114:343-347, 2006.

Paciotti GF, Myer L, Weinreich D, Goia D, Pavel N, McLaughlin RE, Tamarkin L: Colloidal gold: a novel nanoparticle vector for tumour directed drug delivery. Drug Deliv 11:169-183, 2004.

Pan Y, Neuss S, Leifert, Fischler M, Wen F, Simon U, Schmid G, Brandau W, Jahnen-Dechent W: Size-dependent cytotoxicity of GNPs. Small 3:1941-1949, 2007.

Panda BR, Chattopadhyay A: Synthesis of Au nanoparticles at "all" $\mathrm{pH}$ by $\mathrm{H}_{2} \mathrm{O}_{2}$ reduction of $\mathrm{HAuCl}_{4}$. J Nanosci Nanotechnol 7:1911-1915, 2007.

Panyala NR, Peña-Méndez EM, Havel J: Silver or silver nanoparticles: a hazardous threat to the environment and human health? J Appl Biomed 6:117-129, 2008.

Park SJ, Taton TA, Mirkin CA: Array-based electrical detection of DNA with nanoparticle probes. Science 295:1503-1509, 2002.

Patra HK, Banerjee S, Chaudhuri U, Lahiri P, Dasguptha AK: Cell selective response to GNPs. Nanomedicine: Nanotech Biol Med 3:111-119, 2007.

Peña-Méndez EM, Hernández-Fernaud JR, Nagender R, Houška J, Havel: The chemistry of gold clusters in plasma generated with MALDI, Laser desorption ionization and laser ablation from various precursors. Chem Listy 102:s1394-s1398, 2008.

Pernodet N, Fang X, Sun Y, Bakhtina A, Ramakrishnan A, Sokolov J, Ulman A, Rafailovich M: Adverse effects of citrate/GNPs on human dermal fibroblasts. Small 2:766-773, 2006.

Raut CP, Izzo F, Marra P, Ellis LM, Vauthey JN, Cremona F, Vallone P, Mastro A, Fornage BD, Curley SA: Significant long-term survival after radiofrequency ablation of unrespectable hepatocellular carcinoma in patients with cirrhosis. Ann Surg Oncol 12:616-628, 2005.

Räsänen L, Kaipianen-Seppänen O, Myllykangas-Luosujärvi R, Käsnänen T, Pollari P, Saloranta P, Horsmanheimo M: Hypersensitivity to gold sodium thiomalate-induced dermatosis. $\mathrm{Br}$ J Dermatol 141:683-688, 1999.

Rayavarapu RG, Petersen W, Ungureanu C, Post JN, Leeuwen TGV, Manohar S: Synthesis and bioconjugation of GNPs as potential molecular probes for light-based imaging techniques. Int $\mathrm{J}$ Biomed Imaging 2007:29817-29827, 2007.

Roth J, Bendayan M, Carlemalm E, Villiger W, Garavito M: Enhancement of structural preservation and immunocytochemical staining in low temperature embedded pancreatic tissue. J Histochem Cytochem 29:663-671, 1981.

Salata O: Applications of nanoparticles in biology and medicine. J Nanobiotechnol 2:3, 2004.

Sannella AR, Casini A, Gabbiani C, Messori L, Bilia AR, Vincieri FF, Majori G, Severini C: New uses for old drugs. Auranofin, a clinically established antiarthritic metallodrug, exhibits potent antimalarial effects in vitro: Mechanistic and pharmacological implications. FEBS Lett 582:844-847, 2008.

Shaw IC: Gold-based therapeutic agents. Chem Rev 99:2589-2600, 1999.

Svensson A, Möller H, Björkner B, Bruze M, Leden I, Theander J, Ohlsson K, Linder C: Rheumatoid arthritis, gold therapy, contact allergy and blood cytokines. BMC Dermatol 2:2-6, 2002.

Tan WB, Zhang Y: Surface modification of gold and quantum dot nanoparticles with chitosan for bioapplications. J Biomed Mater Res A 75:56-62, 2005.

Traber KE, Okamoto H, Kurono C, Baba M, Saliou C, Soji T, Packer L, Okamoto T: Anti-rheumatic compound aurothioglucose inhibits tumour necrosis factor-a-induced HIV-1 replication in latently infected OM10.1 and Ach2 cells. Int Immunol 11:143-150, 1998.

Triulzi RC, Micic M, Orbulescu J, Giordani S, Mueller B, Leblanc RM: Antibody-gold quantum 
dot-PAMAM dendrimer complex as an immunoglobin immunoassay. Analyst 133:667672, 2008.

Tsvetkov DE, Cheshev PE, Tuzikov AB, Chinarev AA, Pazynina GV, Sablina MA, Gambaryan AS, Bovin NV, Rieben R, Shashkov AS, Nifant'ev NE: Neoglycoconjugates based on dendrimer poly(aminoamides). Russ J Bioorg Chem 28:470-486, 2002.

Vamnes JS, Morken T, Helland S, Gjerdet NR: Dental gold alloys and contact hypersensitivity. Contact Dermatitis 42:128-133, 2000.

Wang W, Chen Q, Jiang C, Yang D, Liu X, Xu S. One-step synthesis of biocompatible gold nanoparticles using gallic acid in the presence of poly-(N-vinyl-2-pyrrolidone). Colloid Surface A 301:73-79, 2007.

Wang X, Inapagolla R, Kannan S, Lieh-Lai M, Kannan RM: Synthesis, characterization, and in vitro activity of dendrimer-streptokinase conjugates. Bioconjugate Chem 18:791-799, 2007.

Wijaya A, Schaffer SB, Pallares IG, Hamad-Schifferli K: Selective release of multiple
DNA oligonucleotides from gold nanorods. ACS Nano 3:80-86, 2009.

Wiwanitkit V, Sereemaspun A, Rojanathanes R: Effect of gold nanoparticles on spermatozoa: the first world report. Fertil Steril 91:e7-e8, 2009.

Wright IH, Vesey CJ: Acute poisoning with gold cyanide. Anaesthesia 41:936-939, 1986.

Wu ML Tsai WJ, Ger J, Deng JF, Tsay SH, Yang MH: Cholestatic hepatitis caused by acute gold potassium cyanide poisoning. Clin Toxicol 39:739-743, 2001.

Zhang Z, Yang X, Zhang Y, Zeng B, Wang S, Zhu T, Roden RB, Chen Y, Yang R: Delivery of telomerase reverse transcriptase small interfering RNA in complex with positively charged single walled carbon nanotubes suppresses tumour growth. Clin Cancer Res 12:4933-4939, 2006.

Zhang J, Atay T, Nurmikko AV: Optical detection of brain cell activity using plasmonic GNPs. Nano Lett 9:519-524, 2009.

Zharov VP, Mercer KE, Galitovskaya EN, Smeltzer MS: Photo thermal nanotherapeutics and nanodiagnostics for selective killing of bacteria targeted with GNPs. Biophys J 90:619-627, 2006. 